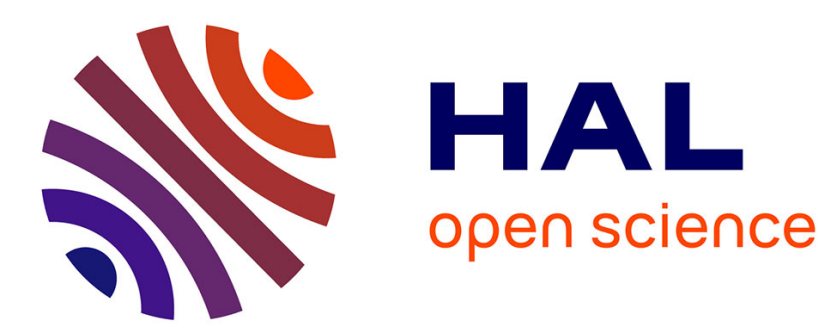

\title{
A Test of the Rational Expectations Hypothesis using data from a Natural Experiment
}

Anna Conte, Peter G. Moffatt, Fabrizio Botti, Daniela T. Di Cagno, Carlo d'Ippoliti

\section{- To cite this version:}

Anna Conte, Peter G. Moffatt, Fabrizio Botti, Daniela T. Di Cagno, Carlo d'Ippoliti. A Test of the Rational Expectations Hypothesis using data from a Natural Experiment. Applied Economics, 2011, pp.1. 10.1080/00036846.2011.597734 . hal-00718703

\section{HAL Id: hal-00718703 https://hal.science/hal-00718703}

Submitted on 18 Jul 2012

HAL is a multi-disciplinary open access archive for the deposit and dissemination of scientific research documents, whether they are published or not. The documents may come from teaching and research institutions in France or abroad, or from public or private research centers.
L'archive ouverte pluridisciplinaire HAL, est destinée au dépôt et à la diffusion de documents scientifiques de niveau recherche, publiés ou non, émanant des établissements d'enseignement et de recherche français ou étrangers, des laboratoires publics ou privés. 


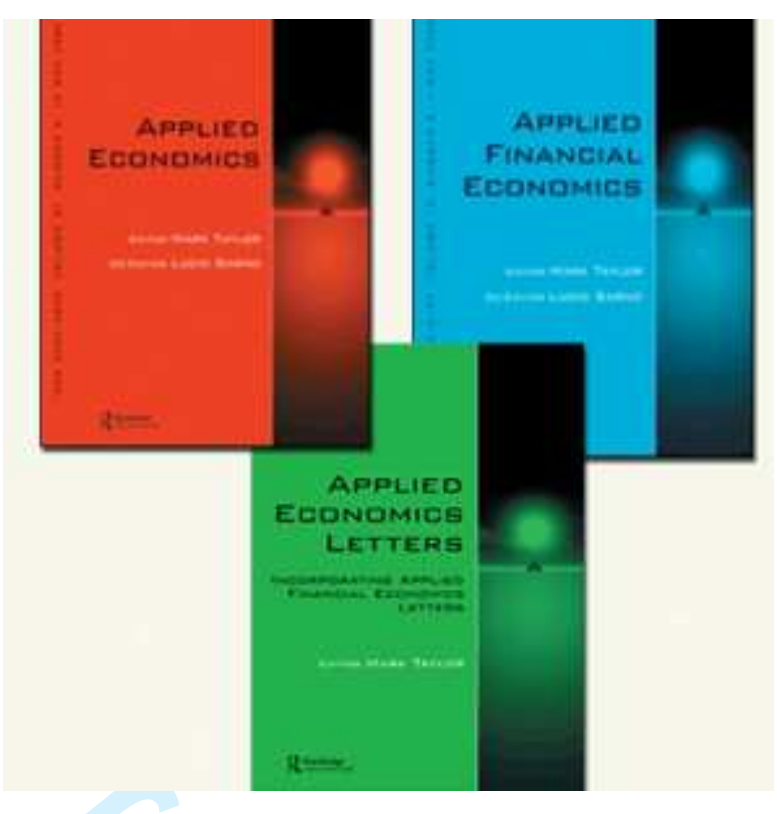

\section{A Test of the Rational Expectations Hypothesis using data from a Natural Experiment}

\begin{tabular}{|r|l|}
\hline Journal: & Applied Economics \\
\hline Manuscript ID: & APE-2010-0264.R1 \\
\hline Journal Selection: & Applied Economics \\
\hline Date Submitted by the \\
Author: & 03-Feb-2011 \\
\hline Complete List of Authors: & $\begin{array}{l}\text { Conte, Anna; Max-Planck-Institut für Ökonomik, Strategic } \\
\text { Interaction Group } \\
\text { Moffatt, Peter; University of East Anglia, School of Economics } \\
\text { Botti, Fabrizio } \\
\text { Di Cagno, Daniela } \\
\text { D'Ippoliti, Carlo }\end{array}$ \\
\hline JEL Code: & $\begin{array}{l}\text { D81 - Criteria for Decision-Making under Risk and Uncertainty < D8 } \\
\text { - Information and Uncertainty < D - Microeconomics, C25 - Discrete } \\
\text { Regression and Qualitative Choice Models < C2 - Econometric } \\
\text { Methods: Single Equation Models < C - Mathematical and } \\
\text { Quantitative Methods }\end{array}$ \\
\hline Keywords: & $\begin{array}{l}\text { Beliefs, Natural Experiments, rational expectations, risky choice, } \\
\text { Discrete choice models }\end{array}$ \\
\hline & \\
\hline
\end{tabular}




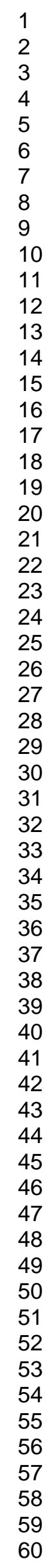

\section{SCHOLARONE ${ }^{m}$ \\ Manuscripts}

7

25

26

27
28

29

30

31

33

34

35

36

37

38

40

41

42

44

45

46

47

48

49

51

52

54

55

57

58

59

60 


\title{
A Test of the Rational Expectations Hypothesis using Data from a Natural Experiment
}

\author{
by \\ Anna Conte, Peter G. Moffatt, Fabrizio Botti, Daniela T. Di Cagno, and Carlo D'Ippoliti
}

\begin{abstract}
Data on contestants' choices in Italian Game Show Affari Tuoi are analysed in a way that separates the effect of risk attitude (preferences) from that of beliefs concerning the amount of money that will be offered to contestants in future rounds. This separate identification is possible by virtue of the fact that, at a certain stage of the game, beliefs are not relevant, and risk attitude is the sole determinant of choice. The rational expectations hypothesis is tested by comparing the estimated belief function with the "true" offer function which is estimated extraneously using data on offers actually made to contestants. We find a close correspondence, leading us to accept the rational expectations hypothesis. The importance of belief-formation is confirmed by the estimation of a mixture model which establishes that the vast majority of contestants are forward-looking as opposed to myopic.
\end{abstract}

JEL Codes: C15; C23; C25; D81.

Key words and phrases: Beliefs; Discrete choice models; extraneous estimators; Natural Experiments; rational expectations; risky choice.

Strategic Interaction Group, Max-Planck Institute of Economics, Jena, Germany and University of Westminster, London, UK: A.Conte@westminster.ac.uk

School of Economics, University of East Anglia, Norwich, UK: P.Moffatt@uea.ac.uk

Department of Economics, Finance and Statistics, University of Perugia: fabrizio.botti@ unipg.it

LUISS Guido Carli, Rome, Italy: ddicagno@luiss.it

University of Rome "La Sapienza”, Rome, Italy: carlo.dippoliti@ uniroma1.it 


\section{A Test of the Rational Expectations Hypothesis using data from a Natural Experiment}

\section{Introduction}

When an individual is faced with a choice problem under risk, that individual's risk attitude is the principal determinant of their choice. However, this assumes that the payoff from the choice is instantaneous. If the payoff is made at some future date, and the eventual payoff is dependent on the state of the world at that future date, or on some intervention by others, then the individual's beliefs of what will pertain at that future date must enter the decision making process. Obvious examples are found in economics: schooling decisions depend on individuals' beliefs about the structure of the labour market that will pertain several years in the future; borrowers base their decision on whether to opt for a fixed-rate mortgage on their beliefs about future movements of interest rates; firms base their investment and production plans on beliefs about the future evolution of consumer preferences.

Researchers analysing such decisions clearly cannot rely solely on choice data, because any observed choice is usually compatible with many different combinations of risk attitudes and beliefs. This is a problem that is frequently encountered in experimental economics, although not all researchers appear to recognise it or to pay due attention to it.

One notable exception is Manski (2002), who analyses the problem in the context of an ultimatum game. He emphasises that the Proposer's decision depends on her subjective probability distribution of the Responder's possible reactions, and that knowledge of the observed decision alone is insufficient to identify the proposer's decision-making process. In contexts such as this, researchers have tended to appeal to rational expectations theory, and to assume that agents form the same beliefs as would a researcher with access to all of the relevant data as well as appropriate econometric estimation facilities and expertise. This, of course, places structure on agent's beliefs, allowing the researcher to isolate risk attitudes (henceforth "preferences"). However, although many tests of the rational expectations hypothesis appear in the macroeconomics literature (see Attfield et al., 1991), there is little evidence of whether agents behave according to the rational expectations hypothesis in microeconomic contexts.

An alternative approach, reviewed by Manski (2004), is to ask individuals directly about their beliefs. Bellemare et al. (2008) follow this approach, again in the context of an ultimatum game. They find that a model estimated with this information on beliefs incorporated, has higher predictive power than a model based on the assumption of rational expectations. However, belief elicitation can itself cause problems: Rutström and Wilcox (2009), in an experiment on the repeated matching pennies game, find that agents tend to alter their strategies when asked to state their beliefs about opponents' behaviour.

In recent years, the analysis of data from television game shows has become a popular means of analysing individuals' behaviour under risk ${ }^{1}$. It is obvious why researchers favour this sort of data. Game shows provide a good natural context in which contestants face well-defined decision problems in a ceteris paribus environment. Furthermore, it cannot be denied that contestants have salient incentives. One game show that scores particularly highly on these criteria is the Italian show Affari Tuoi, data from which is analysed in this paper. This game is played in many different countries under different names and with slightly different rules; the UK version is named Deal or No Deal. Researchers seem to be in agreement on the usefulness of the resulting data: Bombardini and Trebbi (forthcoming) assert that Affari Tuoi "presents several features that we would have chosen, were we to design such an experiment"; Post et al (2008) describe the Dutch version of the same game as having "such desirable features that it almost appears to be designed to be an economics experiment rather than a TV show".

The rules of Affari Tuoi will be explained in detail in Section 2. For the time being, let us simply recognise that the contestant faces a sequence of choice problems, in which the choice is

\footnotetext{
${ }^{1}$ See, among the others, Friend and Blume (1975), Gertner (1993), Metrick (1995), Beetsma and Shotman (2001) and Hartley et al. (2005) for an analysis of individual risk attitude through TV games.
} 
between an uncertain lottery, and a certain amount offered by the "Banker", and that if the Banker's offer is accepted, the game ends.

There has been a large volume of recent research analysing data from the various different versions of this game show (e.g., Andersen at al., (2006, 2007), de Roos and Sarafidis (2010), Deck et al. (2008), Post et al. (2008)). Much of this research has focused, in particular, on the search for the best characterisation of behaviour under risk. A common feature of all of these studies is the realisation that, at each stage of the game, a typical contestant is not treating the choice problem as a single isolated task, but is instead forming beliefs of what will happen in future rounds, and using these beliefs in making their decision in the current round. In particular, they are forming an expectation of what the Banker's offer will be in future rounds, should they stay in the game. It is clear that such beliefs have the potential to influence the current decision. It is also clear that this setting bears similar features to that of the ultimatum game considered earlier, with the attendant difficulties, raised by Manski (2002), in separately identifying preferences and beliefs. Typically, the assumption of rational expectations is implicitly adopted, whereby the inferential problem of predicting the Banker's offer is solved outside the choice model. This is done in a variety of ways, usually based on parametric characterisations.

In this paper, we treat the formation of beliefs about the Banker's offer as the central focus. In particular, by incorporating a predicted Banker's offer equation into the choice model, we are able to estimate the equation that contestants actually use to form beliefs. We are then able to compare this true belief equation with the equation that would be used under the assumption of rational expectations, hence enabling a formal test of the rational expectations hypothesis.

With these objectives in mind, we note that the game show has a peculiar structure: in the final round of the game, contestants' choices unequivocally reveal information on their risk aversion (since there is no contamination from beliefs about future rounds). The information on risk attitude extracted from the choice made in the final round is combined with information on choices from earlier rounds in order to identify the parameters of the belief function that is used by contestants in these earlier rounds.

In addition to testing for rational expectations, we provide an assessment of the validity of another assumption that has been made routinely in previous work: that all contestants are forward-looking. While it may seem natural for contestants to base their decisions on their beliefs of what will unfold in future rounds, it is doubtful that every contestant behaves in this way. We would therefore like to allow for a proportion of the population to be forward-looking, and for the remainder to be "myopic", that is, to base their choice solely on the possible outcomes from the current round. This leads us to a "mixture model", of the type estimated in similar contexts by Conte et al. (2009) and Harrison and Rutström (2008). One of the parameters in the mixture model is the "mixing proportion" which represents the proportion of the population who are forward-looking. This parameter is estimated along with the preference estimates for both models and the belief estimates for the forward-looking model.

In Section 2, the rules of Affari Tuoi are explained in detail. Section 3 provides a theoretical analysis of the choice problem perceived by contestants, and a discussion of the identification problem. In Section 4, we construct the log-likelihood function for the choice model, and describe our chosen method for maximising it. Section 5 presents the results from the choice model, and also reports the result of a test of the rational expectations hypothesis. Section 6 reports on the results of a mixture model which allows the co-existence of myopic and forwardlooking contestants. Section 7 considers a model in which the rational expectations hypothesis is extended to incorporate regularities in the data on Banker's offers. Section 8 concludes.

\section{The game}

Affari Tuoi is a 5-round stop-and-go game between a contestant and a Banker. The game starts with 20 contestants, one from each of the 20 Italian regions. They are each randomly assigned a sealed box, containing one of the 20 prizes displayed in Table 1 . The show begins by contest- 
ants answering a general knowledge question. The first contestant to answer correctly is selected to play the game.

\begin{tabular}{c|c}
\hline$€ 0.01$ & $€ 5,000$ \\
$€ 0.20$ & $€ 10,000$ \\
$€ 0.50$ & $€ 15,000$ \\
$€ 1$ & $€ 20,000$ \\
$€ 5$ & $€ 25,000$ \\
$€ 10$ & $€ 50,000$ \\
$€ 50$ & $€ 75,000$ \\
$€ 100$ & $€ 100,000$ \\
$€ 250$ & $€ 250,000$ \\
$€ 500$ & $€ 500,000$ \\
\hline \hline
\end{tabular}

Table 1: List of prizes as displayed to contestants.

In each of the 5 rounds, the selected contestant opens a fixed number of boxes ( 6 in the first round, then groups of 3 boxes); on each occasion that a box is opened, the cash value of that box is revealed, indicating a sum of money which is no longer available to the contestant.

At the end of each round, the Banker makes a proposal: he either offers "the swap", that is, the opportunity to change her box with one of the remaining boxes of her own choosing; or, he offers a definite amount of money to her to quit the game. Throughout the paper, we refer to this definite money amount as the Banker's offer. If the contestant accepts the Banker's offer, the game ends; otherwise she proceeds to the next round. If the contestant reaches the final round, and rejects the Banker's offer in this round, she receives the content of the box in her possession at that time.

Our sample consists of 298 showings, and therefore contains data on 298 contestants' decisions $^{2}$. Figure 1 shows, for each round, the number of contestants receiving a Banker's offer and the number of contestants accepting that offer. Figure 2 shows the proportion of contestants accepting the Banker's offer by round. It is calculated by dividing the number of contestants accepting an offer in any round by the number of contestants receiving an offer in that round. This proportion is seen to rise dramatically in the course of the game.

In the analysis that follows, we restrict attention to decisions made in rounds 3, 4 and 5, so we lose the four contestants who accept the Banker's offer in round 2, leaving a sample of 294. Our principal reason for restricting attention to the last 3 rounds is that, since offers are rarely accepted in rounds 1 and 2, there is insufficient variability in the data to explain the choice process. We also focus attention solely on the instances when the Banker makes a monetary offer; we do not analyse the behaviour of contestants when offered the "swap", previously mentioned. The reason is that we do not consider the "swap" decision to be informative: a rational contestant must be indifferent between swapping and not swapping. ${ }^{3}$ Of course, this assumes that the contestant has no information whatsoever about the content of their own box. It is a simple matter to test this assumption econometrically. To such a test we now turn.

\footnotetext{
${ }^{2}$ For a more detailed description of the data set used in this paper, see Botti et al. (2007, 2008).

${ }^{3}$ Blavatskyy and Pogrebna (2010) focus attention on the swap in Affari Tuoi.
} 


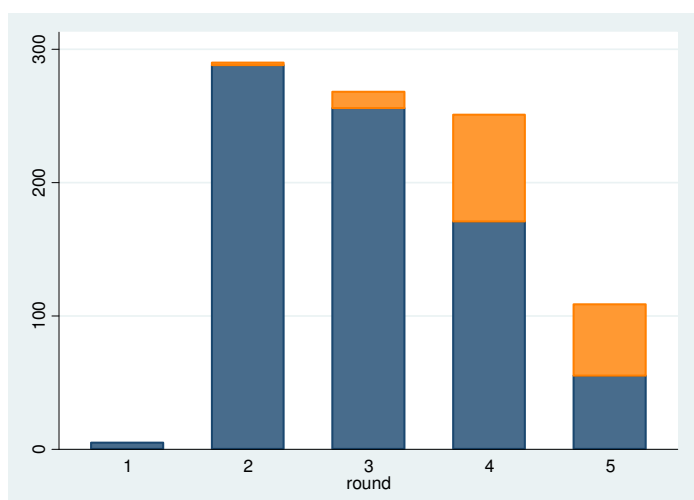

Figure 1: The number of contestants receiving a Banker's offer in each round (column height) and the number of contestants accepting the offer (orange section).

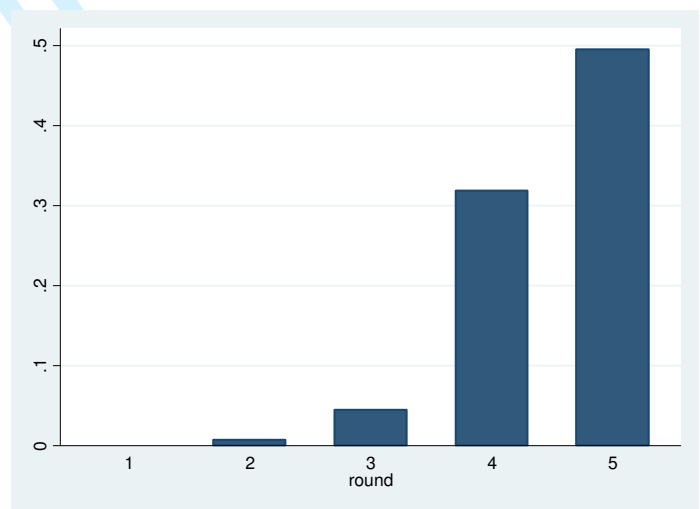

Figure 2: The number of contestants accepting an offer in each round as a proportion of the number receiving an offer in that round.

It is often claimed (e.g. de Roos and Sarafidis, 2010; Mulino et al., 2006) that, in the Italian game, since the Banker knows the contents of the contestant's box, he tends to base his offer on this information. This could raise the possibility of strategic behaviour by contestants: that they base their decision on information extracted from the Banker's offer. Let us briefly investigate this claim. The following table shows the correlation coefficient between the offer measured as a proportion of the expected value of the lottery, and the content of the contestant's box. These correlations are computed separately for the three rounds.

\begin{tabular}{lcc}
\hline \hline & correlation & p-value \\
\hline Round 3 & 0.086 & 0.160 \\
Round 4 & 0.092 & 0.146 \\
Round 5 & -0.045 & 0.636 \\
\hline \hline
\end{tabular}

\footnotetext{
Table 2: Correlation per round between the Banker's offer measured as a proportion of the expected value of the lottery, and the content of the contestant's box.
}

We see that these correlations are small in magnitude, and none of them is significantly different from zero. Hence we are not able to corroborate the claim that the Banker's offer contains information about the content of the contestant's box.

Regardless of this finding, let us investigate whether the contestant is able to extract information, from any source, about the contents of their box. To this end, we simply investigate the determinants of the contestant's decision to accept the "deal". We estimate a random effects probit model of "deal" acceptance, with, as explanatory variables, the expected value of the lot- 
tery $(E V)$, the offer as a proportion of $E V$, the standard deviation of the lottery, and the content of the contestant's box.

\begin{tabular}{cc}
\hline \hline Decision to accept the Banker's offer (“deal”) \\
\hline EV & -0.00090 \\
& $(0.00223)$ \\
Banker's offer $\div E V$ & 2.90676 \\
& $(0.30181)$ \\
Std. Dev. lottery & 0.00777 \\
& $(0.00201)$ \\
Content of contestant's box & -0.00045 \\
& $(0.00065)$ \\
intercept & -2.66549 \\
& $(0.22340)$ \\
\hline Number of contestants(n) & 294 \\
Average number of & 2.15 \\
choices per contestant & -278.26633 \\
\hline Log-likelihood
\end{tabular}

Table 3: Results from a random effect probit regression of the contestants' decision to accept "deal".

The most important conclusion from the results in Table 3 is that the content of the contestant's box appears to have no effect on the contestant's decision. From this we infer that, even if it were possible for the contestant to glean information from the Banker's offer or from another source, there is no evidence that such information is being used by contestants in forming their decisions.

\section{Theoretical Model}

\subsection{Decision Rule}

In any given round (with the exception of the final round), contestants are not evaluating a oneshot lottery, but a sequence of nested lotteries, and it is assumed that they recognise that the offer in later rounds might be higher (or lower) than the one they currently face. Every possible lottery that might be encountered in future rounds needs to be considered. For each of these possible lotteries, an expectation must be formed of the Banker's offer that might be made. Let use define a lottery by a vector $X$, consisting of the prizes that remain. The dimension of the vector $X$ may be 8,5 , or 2 , depending on the round. Let $o f f_{t}^{e}(X)$ be the expectation formed of the Banker's offer that will materialise in future round $t$, given the set of remaining prizes contained in the vector $X$. Note the absence of an $i$ subscript in this expression: it is assumed that all contestants form beliefs in the same way. The precise ways in which it is assumed that beliefs are formed will be revealed in Sections 5 and 7.

Consider the decision of Contestant $i$ in round $t$. In this round, the prizes that remain are contained in the vector $X_{i t}$, and the (actual) Banker's offer is off $f_{i t}$. Assuming expected utility maximisation, Contestant $i$ accepts this offer if:

$$
U_{i}\left(\text { off }_{i t}\right)>E U_{i t}\left(X_{i t}\right), \quad t=3,4,5,
$$

where 


$$
\begin{aligned}
& E U_{i 3}\left(X_{i 3}\right)=\frac{1}{56} \sum_{j=1}^{56} \max \left\{U_{i}\left[o f f_{4}^{e}\left(X_{i 3 j}\right)\right], \frac{1}{10} \sum_{k=1}^{10} \max \left[U_{i}\left[o f f_{5}^{e}\left(X_{i 3 j k}\right)\right], E U_{i}\left(X_{i 3 j k}\right)\right]\right\} \\
& E U_{i 4}\left(X_{i 4}\right)=\frac{1}{10} \sum_{j=1}^{10} \max \left\{U_{i}\left[o f f_{5}^{e}\left(X_{i 4 j}\right)\right], E U_{i}\left(X_{i 4 j}\right)\right\} \\
& E U_{i 5}\left(X_{i 5}\right)=E U_{i}\left(X_{i 5}\right)
\end{aligned}
$$

The terms on the left-hand side of (2), $E U_{i t}\left(X_{i t}\right), t=3,4,5$, represent the perceived value to Contestant $i$ from continuing with the game beyond round $t$. The various components of the right-hand-side are explained as follows. $X_{i 3 j}, j=1, \ldots, 56$, represents one of the $\left(\begin{array}{l}8 \\ 5\end{array}\right)=56$ possible lotteries deriving from the third-round lottery $X_{i 3}$, that Contestant $i$ might face in round 4 by opening 3 of the remaining 8 boxes. Conditional on lottery $X_{i 3 j}$ being realised in the fourth round, there are $\left(\begin{array}{l}5 \\ 2\end{array}\right)=10$ possible lotteries in the fifth round: $X_{i 3 j k}, k=1, \ldots, 10$. Similarly $X_{i 4 j}, j=1, \ldots, 10$, represents one of the $\left(\begin{array}{l}5 \\ 2\end{array}\right)=10$ possible lotteries deriving from the fourth-round lottery $X_{i 4}$, that might be confronted in round 5 by opening 3 of the remaining 5 boxes. $X_{i 5}$ contains only two prizes - the two that remain in the fifth round.

$U_{i}\left[o f f_{t}^{e}(X)\right]$ is the utility of the offer that Contestant $i$ expects to receive in a future round $t$, given that the prizes remaining at that time are $X . E U_{i}(X)$ is the expected utility perceived by Contestant $i$ of a lottery consisting of the prizes $X$.

Let us note in particular the third line of (2). $E U_{i 5}\left(X_{i 5}\right)$ is simply the expected utility of the lottery consisting of the two outcomes remaining in round 5. A key feature of this quantity is that it does not depend in any way on beliefs.

\subsection{Separate Identification of Preferences and Beliefs}

The problem of separating beliefs from preferences has been raised in Section 1. We remarked there that, as a way of overcoming this problem, researchers commonly rely on the hypothesis of rational expectations. For example, de Roos and Sarafidis (2010) and Mulino et al. (2006) use data on offers made in all showings in order to form predictive equations for the Banker's offer in each round. Then, they use the prediction thus obtained as the contestant's belief. Andersen et al (2006, 2007) and Post et al. (2008) do similar.

In this paper, we take a step forwards from the straightforward assumption of rational expectations. Since we recognise that Affari tuoi provides a suitable environment to estimate both preferences and beliefs in the absence of any restrictive assumptions about the way that beliefs are formed, we are able to develop a procedure for testing whether such beliefs are in fact formed according to rational expectations theory. This is possible because, in round 5, contestants' choices do not involve any belief formation. The contestant's problem in round 5 is just a straightforward choice between two lotteries: one with two equi-probable prizes; the other being a certainty of the Banker's offer. It is only in rounds 3 and 4 that beliefs are formed. Under the reasonable assumption of invariance over time of contestants' preferences, we are therefore able to combine the data from round 5 choices with that from rounds 3 and 4 in order to estimate preferences and beliefs jointly. Of course, in doing this we are making the further identifying assumption that the belief functions are the same for all contestants. In making such an assump- 
tion, we are simply following the conventions of those who have assumed rational expectations (e.g. Post et al., 2008).

An important point is that the distribution of the risk aversion parameter in round 5 is truncated from above, for the obvious reason that the most risk-averse contestants are likely leave the game in earlier rounds. This might raise concerns of attrition or selection bias in estimation. This would indeed be a problem if we were estimating preferences using data from only round 5. But the simultaneous use of data from all three rounds enables us to estimate the complete distribution of preferences over the population. It is intuitively helpful to imagine the following sequence being repeated until convergence: first, the preferences of the contestants reaching round 5 are estimated; then these contestants' choices in earlier rounds are used to deduce their beliefs; the beliefs thus estimated are extended to contestants who left the game before round 5; finally, the preferences of these other contestants are deduced, filling in the truncated upper tail of the risk attitude distribution.

For readers not satisfied with this explanation, we have also carried out Monte-Carlo simulations in order to confirm the validity of our estimation procedure. For the purpose of the simulation, we assume that the game consists of only two rounds, corresponding to the "fourth" and "fifth" rounds of the real game, and that there are 300 contestants. We have used actual lotteries and offers from the fourth and fifth rounds of the real game to generate the situations assumed in the simulated game. All that is simulated is the contestants' decisions. For each of 1000 replications, two models are estimated using the method of maximum simulated likelihood (see Section 4). The first model is one that is applicable to a "selection" sample similar to the real data. That is, individuals who accept the deal in the "fourth" round are not observed in the "fifth" round. The second model is one that uses information on both decisions by every contestant, whether or not they accept the deal in the "fourth" round. Note that this second model is indisputably free of any selection problems. Both models are estimated using the same simulated data.

Further details of the simulation are presented in Appendix 1. The important conclusion from the simulation is that both beliefs and preferences appear to be consistently estimated in both models. Hence it is established that consistency is achieved even with the most risk-averse contestants being selected out in early rounds.

\section{The econometric choice model}

In this section we introduce the econometric model that simultaneously estimates preferences and beliefs. We assume throughout that contestants are expected utility maximisers. We further assume that contestant $i$ has the Constant Absolute Risk Aversion (CARA) utility function ${ }^{4}$, given by:

$$
U_{i}(x)=\frac{1-\exp \left(-r_{i} x\right)}{1-\exp \left(-r_{i} x_{\max }\right)},
$$

where $x$ is the outcome ${ }^{5}, x_{\max }$ is the highest possible outcome (500 thousand euros). Note that the functional form of (3) ensures that $U(0)=0$ and $U\left(x_{\max }\right)=1 . \quad r_{i}$ is the coefficient of absolute risk aversion for contestant $i$. We assume, in the spirit of Holt and Laury (2002), that this coefficient is distributed across the population according to:

\footnotetext{
${ }^{4}$ We have also used a CRRA and an Expo-power specification, assuming non-zero lifetime wealth as a parameter to be estimated, along similar lines to Andersen et al. (2006). We find that the estimate of the lifetime wealth parameter is not significantly different from zero. However, the use of these specifications never significantly improves the fit over the CARA specification (cf Andersen et al, 2006; de Roos and Sarafidis, 2010; Post et al, 2008). The various results are available from the authors upon request.

${ }^{5}$ Here, and throughout the paper, we measure money amounts in units of $€ 1,000$.
} 


$$
r_{i} \sim N\left(\mu_{r}, \sigma_{r}^{2}\right){ }^{6}
$$

The latent variable underlying a contestant $i$ 's choice in round $t$ is:

$$
y_{i t}^{*}=U_{i}\left(o f f_{i t}\right)-E U_{i t}\left(X_{i t}\right)+\varepsilon_{i t} .
$$

Here $\varepsilon_{i t}$ is a Fechner-type error term (Hey and Orme, 1994), with $\varepsilon_{i t} \sim N\left(0, \sigma_{\varepsilon}^{2}\right)$. It has the interpretation of a computational error in the calculation of utilities and expected utilities. This error is assumed to be homoscedastic and uncorrelated with all other variables in the model. Let us define the binary variable $y_{i t}$ to take the value 1 if contestant $i$ accepts the Banker's offer in round $t$, and the value -1 otherwise. The relationship between the observable variable $y_{i t}$ and the latent variable $y_{i t}^{*}$ is then given by:

$$
\begin{array}{ccc}
y_{i t}=1 & \text { if } & y_{i t}^{*}>0 \\
y_{i t}=-1 & \text { if } & y_{i t}^{*} \leq 0 .
\end{array}
$$

It is clear that for each contestant, we observe either a sequence of minus-ones (if the contestant never accepts the money offer) or a sequence of minus-ones followed by a plus-one (if the contestant accepts an offer). Let $f\left(y_{i t} \mid \boldsymbol{\theta}\right)$ be the probability of the choice observed for contestant $i$ in round $t$, conditional on the values of the model's parameters which are assembled in the vector $\theta$. From (4) and (5), this probability is given by:

$$
f\left(y_{i t} \mid \boldsymbol{\theta}\right)=\Phi\left(y_{i t} \times \frac{U_{i}\left(o f f_{i t}\right)-E U_{i t}\left(X_{i t}\right)}{\sigma_{\varepsilon}}\right) .
$$

Contestant $i$ 's likelihood contribution is the joint probability of observing the sequence of outcomes $\left(y_{i 3}, \cdots, y_{i T_{i}}\right)$, where $T_{i}$ (either 3,4 , or 5 ) is the round in which the game ends for contestant $i$. Given the assumption of independence between rounds, this is given by:

$$
L_{i}(\boldsymbol{\theta})=\prod_{i=3}^{T_{i}} f\left(y_{i t} \mid \boldsymbol{\theta}\right)
$$

We also allow for the possibility of sub-optimal behaviour, by introducing a tremble parameter, $\omega(0 \leq \omega \leq 1)$ (Moffatt and Peters, 2001). This represents the probability that the contestant loses concentration and chooses completely at random between the two alternatives. With this additional parameter ${ }^{7}$, contestant $i$ 's likelihood contribution becomes:

$$
L_{i}(\boldsymbol{\theta}, \omega)=\prod_{t=3}^{T_{i}}\left\{(1-\omega) f\left(y_{i t} \mid \boldsymbol{\theta}\right)+\frac{\omega}{2}\right\}
$$

\footnotetext{
${ }^{6}$ This hypothesis has been used in a similar context by Botti et al. (2008) and in different contexts by Araña and León (2006).

${ }^{7}$ In view of the constraint $0 \leq \omega \leq 1$, the parameter that is in fact estimated is $\psi$ where $\omega=\exp (\psi) /(1+\exp (\psi))$. After estimation of $\psi$, an estimate of $\omega$ is deduced, and a standard error is found using the delta method (Oehlert, 1992). Other parameters that are constrained, such as $\sigma_{r}(\geq 0)$ and $\sigma_{\varepsilon}(\geq 0)$ are estimated using similar techniques.
} 
To understand how the maximum simulated likelihood technique has been applied to this problem, we simply note that the risk attitude of contestant $i$ may be written as $r_{i}=\mu_{r}+\eta_{i}$, where $\eta_{i} \sim N\left(0, \sigma_{r}^{2}\right)$. Note also that $\boldsymbol{\theta}$ in (10) includes $\mu_{r}$, but not $\eta_{i}$. We can integrate $\eta_{i}$ out to obtain

$$
L_{i}(\boldsymbol{\theta}, \omega)=\int_{-\infty}^{+\infty} \prod_{t=3}^{T_{i}}\left\{(1-\omega) f\left(y_{i t} \mid \boldsymbol{\theta}, \eta_{i}\right)+\frac{\omega}{2}\right\} \frac{1}{\sigma_{r}} \phi\left(\frac{\eta_{i}}{\sigma_{r}}\right) d \eta_{i}
$$

Following Lerman and Manski (1981), this integral can be approximated by a sample average of the integrand computed drawing $R$ numbers from a standard normal distribution. This way we obtain an unbiased estimator of the integral in (10), with a variance that goes to zero as $R$ increases.

The full sample log-likelihood is given by:

$$
\log L(\boldsymbol{\theta}, \omega)=\sum_{i=1}^{n} \log \left[L_{i}(\boldsymbol{\theta}, \omega)\right]
$$

\section{Estimation of the choice model and a test of rational expectations}

In this Section, we estimate the model constructed in the previous section, using the method of maximum simulated likelihood. Our sample consists of 294 players observed making 2.15 choices on average. In each model, integration over $\eta_{i}$ (see (10)) is performed by simulation using 100 draws for each contestant based on Halton sequences (Train, 2003). We adopt this procedure in preference to the more commonly used Gauss-Hermite quadrature, since, given the complexity of the model, the computational burden is considerably lower for the former than for the latter.

In the spirit of de Roos and Sarafidis (2010), Mulino et al. (2006), Andersen et al (2006, 2007) and Post et al. (2008), we make the following assumption about the formation of expectations of the Banker's offer. The expectations of the fourth-and fifth-round offers depend on the Expected Value of the lottery $(E V)$ according to:

$$
\begin{aligned}
& \operatorname{off}_{4}^{e}(.)=\beta_{4} E V(.) \quad \beta_{4}>0 \\
& \operatorname{off}_{5}^{e}(.)=\beta_{5} E V(.) \quad \beta_{5}>0 .
\end{aligned}
$$

That is, it is assumed that contestants predict the offer in round 4 to be some fixed multiple $\beta_{4}$ of the expected value of the prizes remaining in that round; and they similarly predict the offer in round 5 to be a multiple $\beta_{5}$ of the expected value of prizes remaining in that round.

There are two possible approaches to the estimation of the parameters $\beta_{4}$ and $\beta_{5}$ in (12). The first is to follow the authors cited in the previous paragraph by obtaining "extraneous estimates" (Durbin, 1953), using data on Banker's offers in all showings. Then these extraneous estimates are treated as known parameters in the estimation of the choice model. This is constrained estimation, in the sense that it assumes rational expectations. The alternative approach is to estimate $\beta_{4}$ and $\beta_{5}$ freely within the framework of the choice model. This is referred to as unconstrained estimation. It allows a violation in the assumption of rational expectations.

Table 4 contains results from both unconstrained (column 1) and constrained (column 2) models. In the first column, we see that $\beta_{4}$ and $\beta_{5}$ are both estimated with high precision, and that the estimate of $\beta_{5}$ is significantly larger in magnitude than that of $\beta_{4}$. This simply confirms that contestants correctly expect the Banker to become more generous as the game progresses.

The second column of the table shows the estimates of the model with the parameters $\beta_{4}$ and $\beta_{5}$ constrained to equal the values obtained by performing (extraneous) regressions of actual 
offer on $E V$, using the entire data set. We firstly see that the estimates obtained in the unconstrained model are not significantly different from those obtained in the extraneous regressions, which is loosely consistent with the rational expectations hypothesis. We further note that a likelihood ratio test of the hypothesis that the parameters exactly equal their extraneous estimates gives the $\chi^{2}(2)$ statistic $2 \times(236.53-235.54)=1.97$, which is not significant. We therefore conclude that, under the auxiliary hypothesis of the belief function given in (12), we have no evidence to reject the hypothesis of rational expectations.

\begin{tabular}{|c|c|c|}
\hline & $\begin{array}{l}\text { Estimation with beliefs un- } \\
\text { constrained }\end{array}$ & $\begin{array}{l}\text { Beliefs formed under ra- } \\
\text { tional expectations }\end{array}$ \\
\hline$\mu_{r}$ & $\begin{array}{c}0.02410 \\
(0.00216)\end{array}$ & $\begin{array}{c}0.02335 \\
(0.00172)\end{array}$ \\
\hline$\sigma_{r}$ & $\begin{array}{c}0.01778 \\
(0.00196)\end{array}$ & $\begin{array}{c}0.01633 \\
(0.00142)\end{array}$ \\
\hline$\sigma_{\varepsilon}$ & $\begin{array}{c}0.01284 \\
(0.01099)\end{array}$ & $\begin{array}{c}0.01956 \\
(0.00788)\end{array}$ \\
\hline$\omega$ & $\begin{array}{c}0.06185 \\
(0.02701)\end{array}$ & $\begin{array}{c}0.05910 \\
(0.02516)\end{array}$ \\
\hline \multirow{3}{*}{$\beta_{4}$} & \multicolumn{2}{|c|}{$4^{\text {th }}$ round beliefs equation: $\quad$ off $f_{4}()=.\beta_{4} E V()}$. \\
\hline & $\begin{array}{c}0.38340 \\
(0.02901)\end{array}$ & 0.33170 \\
\hline & \multicolumn{2}{|c|}{$\mathbf{5}^{\text {th }}$ round beliefs equation: $\quad$ off $f_{5}()=.\beta_{5} E V()}$. \\
\hline$\beta_{5}$ & $\begin{array}{c}0.54627 \\
(0.04672)\end{array}$ & 0.56674 \\
\hline $\begin{array}{l}\text { Number of contest- } \\
\text { ants (n) }\end{array}$ & 294 & 294 \\
\hline $\begin{array}{l}\text { Average number of } \\
\text { choices per contest- } \\
\text { ant }\end{array}$ & 2.15 & 2.15 \\
\hline Log-likelihood & -235.54346 & -236.52784 \\
\hline $\begin{array}{l}\text { Table 4: Estimates from t } \\
\text { CARA (3). The estimatio } \\
\text { are shown in parentheses } \\
\text { method. The first column } \\
\text { and } \beta_{5} \text { are constrained to } s\end{array}$ & $\begin{array}{l}\text { model defined in (11) and (12) } \\
\text { echnique used is maximum sim } \\
\text { Some of the standard errors } h \\
\text { esents unconstrained estimates } \\
\text { sfy the rational expectations hy }\end{array}$ & $\begin{array}{l}\text { assumed utility functional } \\
\text { d likelihood. Standard erro } \\
\text { een obtained using the de } \\
\text { he second, the parameters } \\
\text { esis. }\end{array}$ \\
\hline
\end{tabular}

Figures 3 and 4 present, for rounds 4 and 5 respectively, graphical comparisons between the belief functions estimated using the choice model, and those estimated extraneously using actual offers, data on which is also shown in the graphs. In each case, we see that the estimated belief function is impressively close to the extraneous estimate, providing further evidence in favour of rational expectations. 


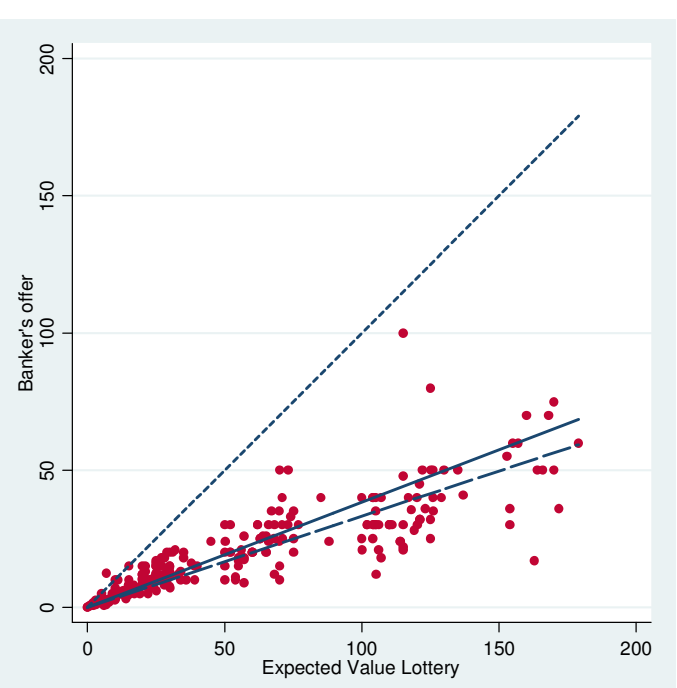

Figure 3: Banker's offer against $E V$ in round 4. The dotted line is a $45^{\circ}$-line. The points of the scatter represent Banker's offers actually made in round 4 of different showings of the game. The superimposed continuous line represents the prediction according to the (unconstrained) estimated belief function in Table 4 Column 1. The dashed line represents the OLS prediction of the Banker's offer using the belief function (12), whose (extraneous) estimate appears in Table 4 Column 2.

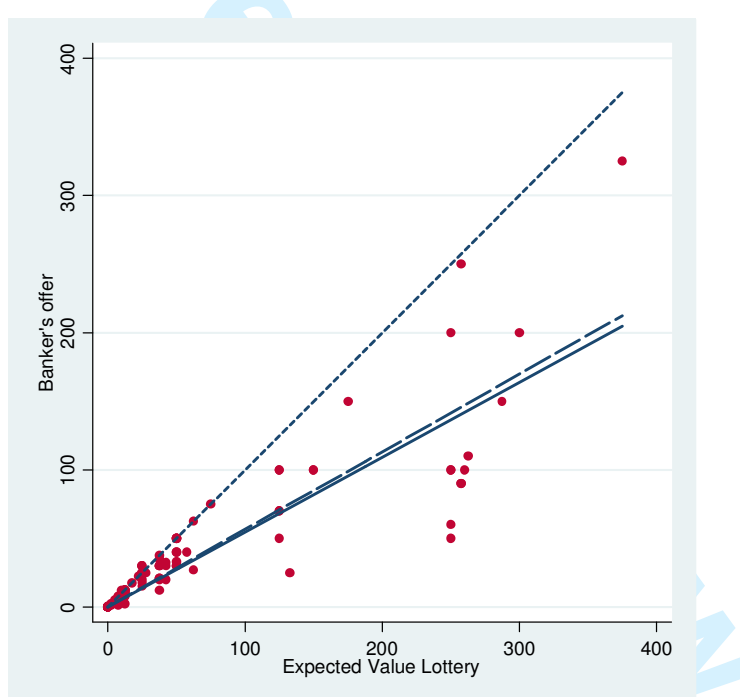

Figure 4: Banker's offer against $E V$ in the round 5. The dotted line is a $45^{\circ}$-line. The points of the scatter represent Banker's offers actually made in round 5 of different showings of the game. The superimposed continuous line represents the prediction according to the (unconstrained) estimated belief function in Table 4 Column 1. The dashed line represents the OLS prediction of the Banker's offer using the belief function (12), whose (extraneous) estimate appears in Table 4 Column 2.

Let us complete this section by briefly considering the other estimates appearing in Table 4. The significantly positive estimates of $\sigma_{r}$ vindicate the assumption of varying risk attitude over the population ${ }^{8}$. The Fechner error parameter, $\sigma_{\varepsilon}$, is significantly different from zero

\footnotetext{
${ }^{8}$ Parameters representing standard deviations of error terms, and tremble probabilities, are clearly constrained to be non-negative, and the hypothesis under test is one for which the parameter of interest is on the boundary of the parameter space. Many authors have acknowledged the problems that arise in this situation (see, for example, Hey and Orme, 1994, footnote 17, Moffatt and Peters, 2001). There is usually a simple remedy: for a test with size 0.05 , the
} 
in the constrained model, although it is not in the unconstrained model. This suggests that, after allowing for heterogeneity in the risk aversion parameter, some computational error remains to be explained. Finally, the tremble parameter is statistically significant. Its magnitude (in both models) indicates that contestants lose concentration on around $6 \%$ of occasions. This is broadly in line with estimates obtained elsewhere in the literature (see, for example, Loomes et al., 2002).

\section{A mixture model of myopic and forward-looking behaviour}

Throughout the analysis so far, we have assumed that contestants are forward-looking. That is, they consider the possible outcomes in future rounds when forming a decision during the current round. However, it is not obvious that all contestants are forward-looking. ${ }^{9}$ Some might be "myopic", and treat each round as an isolated risky choice problem. A model that allows for the co-existence of both types is a finite mixture model. Such a model is estimated in this Section.

One reason for estimating the mixture model is that it is important to know whether a sizeable proportion of subjects are myopic. In Section 3.2, it was explained that self-selection is not an issue since, although the most risk-averse contestants tend to leave the game early, this does not bias the estimates of either the parameters of the distribution of risk attitude $\left(\mu_{r}\right.$ and $\left.\sigma_{r}\right)$, or the belief parameters $\left(\beta_{4}\right.$ and $\left.\beta_{5}\right)$. However, this reasoning only applies if contestants actually have a forward-looking perspective. The presence of myopic contestants in the sample can introduce an attrition bias in the estimation of the forward-looking model: these contestants have a higher probability of leaving the game early, since they neglect the prospect of generous offers in later rounds. Ideally, therefore, we hope for the proportion of myopic subjects to be zero.

We continue to denote as $L_{i}$ contestant $i$ 's likelihood contribution (10) under the assumption of forward-looking behaviour. We also introduce $L_{i}^{\text {myopic }}$ to be contestant $i$ 's likelihood contribution under the hypothesis that she behaves myopically. $L_{i}^{\text {myopic }}$ is the same as $L_{i}$ in (10), except that the expected utility term $E U_{i t}\left(X_{i t}\right)$, introduced in (2) for forward-looking contestants, no longer takes account of the outcomes of future rounds; for myopic contestants, $E U_{i t}\left(X_{i t}\right)$ is simply the expected utility of the lottery consisting of the prizes remaining in round $t$.

Let $\pi(0 \leq \pi \leq 1)$ be the mixing proportion, which is the proportion of the population who are forward-looking. Contestant $i$ 's likelihood contribution in the mixture model is then:

$$
L_{i}^{\text {mixture }}=(1-\pi) L_{i}^{\text {myopic }}+\pi L_{i} .
$$

Table 5 reports the parameter estimates for the mixture model, alongside estimates from a pure-myopic model and a pure-forward looking model. The estimates from the pure-forwardlooking model are the same as those from the first column of Table 4, and are reproduced here in order to facilitate comparison. Firstly and most importantly, the mixing proportion is estimated, with reasonable precision, to be 0.911 (with 95\% confidence interval $0.856<\pi<0.966$ ). This implies that around $91 \%$ of the population are forward-looking and only around $9 \%$ are myopic. The key conclusion from the analysis in this Section is therefore that it is safe to assume that forward-looking behaviour prevails. This is a welcome result, since it means that the attrition bias resulting from the presence of myopic contestants in the sample is not likely to be severe.

0.10 column from tables should be consulted to obtain the appropriate critical value. This remedy has been prescribed in a more general context by Godfrey (1988, p.94).

${ }^{9}$ Bone et al. (2003) investigate the possibility that people might not be forward-looking in a dynamic setting, and provide explanations for those who do not comply with a forward-looking behavior. 
Let us now focus on the estimates of the mixture model (third and fourth columns of Table 5). Comparing the estimates of mean risk attitude $\left(\mu_{r}\right)$ for the two types, we note first that myopic types are, on average, more risk averse than forward-looking types. We further note that the estimate of $\mu_{r}$ for myopic contestants (0.068) is almost six times as large as that estimated on the assumption that all subjects are myopic (0.01236; first column). The explanation for this difference is straightforward: when the myopic model is forced to explain the behaviour of forward-looking contestants, their tendency to reject Banker's offers is interpreted as straightforward risk-lovingness, and it is inevitable that the estimate of the risk aversion parameter will be very low. ${ }^{10}$

\begin{tabular}{|c|c|c|c|c|}
\hline & $\begin{array}{c}\text { All contestants } \\
\text { Myopic }\end{array}$ & $\begin{array}{c}\text { All contestants } \\
\text { Forward-looking }\end{array}$ & \multicolumn{2}{|c|}{ Mixture model } \\
\hline \multirow[b]{2}{*}{$\mu_{r}$} & \multirow[b]{2}{*}{$\begin{array}{c}0.01236 \\
(0.00090)\end{array}$} & \multirow[b]{2}{*}{$\begin{array}{c}0.02410 \\
(0.00216)\end{array}$} & Myopic type & Forward-looking type \\
\hline & & & $\begin{array}{c}0.06827 \\
(0.00031)\end{array}$ & $\begin{array}{c}0.02188 \\
(0.00183)\end{array}$ \\
\hline$\sigma_{r}$ & $\begin{array}{c}0.00639 \\
(0.00156)\end{array}$ & $\begin{array}{c}0.01778 \\
(0.00196)\end{array}$ & $\begin{array}{c}0.00074 \\
(0.00025)\end{array}$ & $\begin{array}{c}0.01687 \\
(0.00176)\end{array}$ \\
\hline$\sigma_{\varepsilon}$ & $\begin{array}{c}0.03692 \\
(0.00882)\end{array}$ & $\begin{array}{c}0.01284 \\
(0.01099)\end{array}$ & $\begin{array}{c}0.00004 \\
(0.00047)\end{array}$ & $\begin{array}{c}0.01585 \\
(0.00834)\end{array}$ \\
\hline \multirow{3}{*}{$\beta_{4}$} & \multirow{3}{*}{-} & $\begin{array}{c}4^{\text {th }} \text { round beliefs eqn.: } \\
\text { off }_{4}(.)=\beta_{4} E V(.)\end{array}$ & \multirow{3}{*}{ - } & $\begin{array}{c}4^{\text {th }} \text { round beliefs eqn.: } \\
\text { off }_{4}(.)=\beta_{4} E V(.)\end{array}$ \\
\hline & & $\begin{array}{c}0.38340 \\
(0.02901)\end{array}$ & & $\begin{array}{c}0.39053 \\
(0.03053)\end{array}$ \\
\hline & & $\begin{array}{c}5^{\text {th }} \text { round beliefs eqn.: } \\
\quad \text { off }_{5}(.)=\beta_{5} E V(.)\end{array}$ & & $\begin{array}{c}5^{\text {th }} \text { round beliefs eqn.: } \\
\text { off } f_{5}(.)=\beta_{5} E V(.)\end{array}$ \\
\hline$\beta_{5}$ & - & $\begin{array}{c}0.54627 \\
(0.04672)\end{array}$ & - & $\begin{array}{c}0.55738 \\
(0.04995)\end{array}$ \\
\hline$\omega$ & $\begin{array}{c}0.07275 \\
(0.03687)\end{array}$ & $\begin{array}{c}0.06185 \\
(0.02701)\end{array}$ & \multicolumn{2}{|c|}{$\begin{array}{c}0.00087 \\
(0.00402)\end{array}$} \\
\hline$\pi$ & - & - & \multicolumn{2}{|c|}{$\begin{array}{c}0.91112 \\
(0.02810)\end{array}$} \\
\hline $\begin{array}{l}\text { Number of con- } \\
\text { testants }(n)\end{array}$ & 294 & 294 & \multicolumn{2}{|c|}{294} \\
\hline $\begin{array}{l}\text { Average number } \\
\text { of choices per } \\
\text { contestant }\end{array}$ & 2.15 & 2.15 & \multicolumn{2}{|c|}{2.15} \\
\hline Log-likelihood & -261.97520 & -232.54020 & \multicolumn{2}{|c|}{-227.41220} \\
\hline
\end{tabular}

Table 5: Estimates from the myopic model, the forward looking model, and the mixture model defined in (13). Belief functions are defined in the Table. The assumed utility functional is CARA. Maximum simulated likelihood used in estimation. Standard errors are shown in parentheses. Some of the standard errors have been obtained using the delta method. The parameter $\pi$ represents the proportion of the population who are of the forward-looking type.

The estimated standard deviation of risk attitude, $\sigma_{r}$, for myopic types, is much smaller in the mixture model (0.00074), than in the model assuming all individuals are myopic (0.0064). This difference simply reflects the fact that the two types differ quite markedly in their risk attitude, so a model that assumes all individuals are of one type will inevitably over-estimate the spread of risk attitude. The estimates obtained in the mixture model of $\mu_{r}$ and $\sigma_{r}$ for forwardlooking types are very close to the estimates obtained in the model that assumes that all indi-

\footnotetext{
${ }^{10}$ See de Roos and Sarafidis (2010) and Mulino et al. (2006) for a more detailed explanation.
} 
viduals are forward-looking (Table 4, first column). This is for the simple reason that the majority of individuals are forward-looking, as indicated by our high estimate of $\pi$ in the mixture model. The same reasoning applies to the two parameters $\beta_{4}$ and $\beta_{5}$, whose estimates under the mixture model agree closely with those in the first column of Table 4 .

The magnitude of the computational error, as represented by $\sigma_{\varepsilon}$, is still small in the mixture model, but is significantly smaller for myopic types (0.00004), than in the model that assumes all individuals are myopic (0.037; Table 5, first column). The reason for this is similar to that advanced above in the context of the parameter $\sigma_{r}$.

The tremble probability, $\omega$, is assumed to be the same for both types in the mixture model $^{11}$, and we see that its estimate is small and insignificant.

The posterior probability of each contestant being of the forward-looking type can be computed using Bayes' rule, as follows:

$$
P\left(i=\text { forward } \mid y_{i 3}, \cdots, y_{i T_{i}}\right)=\frac{\pi L_{i}}{L_{i}^{\text {mixture }}}
$$

Its distribution over the 294 contestants is shown in Figure 5. As expected, the majority of contestants have a high posterior probability of being of the forward-looking type.

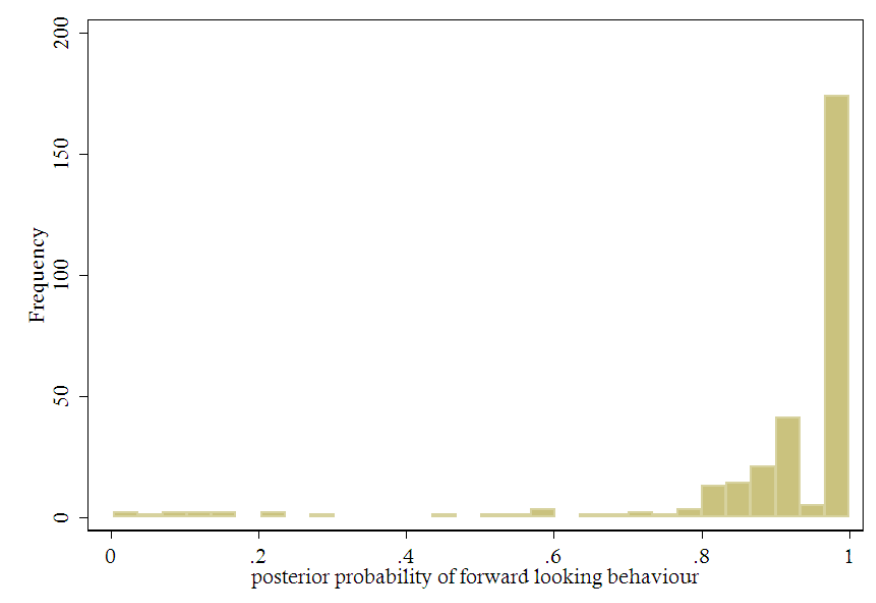

Figure 5: A histogram of the posterior probabilities of being a forward looking type over the sample of 294 contestants.

In unreported work, we also estimate the choice model under the hypothesis that contestants are not fully forward-looking, but look just one-step-ahead. That is, when in round 3 they only consider all the possible lotteries and the consequent offers they might get in round 4 . Unfortunately, Affari Tuoi is such that the sequence of rounds is not sufficiently long to capture the difference between the one-step-ahead model and the forward-looking one; these two models predict different behaviour only in round 3. A mixture model has been estimated with these two forward-looking types, and another model estimated with myopic behaviour as a third type. These mixture models fail to converge, and we attribute this to the inability of the data to distinguish between the two types of forward-looking behaviour.

This is not to say that this is not an interesting research question. We have firmly established that the vast majority of contestants are forward-looking, but it is not clear how far forward-looking agents are looking ahead. We therefore encourage researchers with access to data from games with more rounds to perform similar analysis to that carried out here, in order to address this important question.

\footnotetext{
${ }^{11}$ We know of no reason to presume that one type of individual trembles more than the other.
} 


\section{Alternative specification of the belief function}

The models estimated so far have assumed the simple specification (12) for the determination of the Banker's offer. According to that specification, the expectation of the Banker's offer is simply a positive constant times the expected value of the remaining prizes, with a higher constant being estimated for the fifth round than for the fourth round.

In this section, we take a closer look at the data on Banker's offers, in order to consider whether there might exist a superior specification from which the Banker's offer may be predicted. The relevant analysis is presented in Appendix 2.

Again, the data from rounds 4 and 5 are considered separately. The data has a number of striking features which are discussed in some detail in Appendix 2. The first is the positive skew seen in both EV and the Banker's offer. The second is the fanning-out in the scatter-plots. These two features make it appropriate to consider a log-linear specification. A third important feature is that, in round 5, there is clear upper-censoring in the offer data: although the offer rarely exceeds the expected value of the remaining prizes, there is a tendency for the offer to be exactly equal to the expected value whenever the latter is relatively low. Estimation for round 5 should incorporate this upper censoring. Belief functions that incorporate both of these data features are given by:

$$
\begin{gathered}
\text { off }_{4}=\exp \left[\gamma_{4}+\beta_{4} \log (E V)\right] \\
\text { off }_{5}=\min \left[E V, \exp \left(\gamma_{5}+\beta_{5} \log (E V)\right)\right]
\end{gathered}
$$

As explained fully in Appendix 2, the parameters of (15) are estimated using log-linear regression, while those of (16) are estimated using log-linear (upper-censored) tobit.

As when belief function (12) was estimated in section 5, data on Banker's offers in all showings is used to estimate (15) and (16). The results are:

$$
\begin{gathered}
o f f_{4}^{e}=\exp [-0.460+0.857 \log (E V)] . \\
o f f_{5}^{e}=\min [E V, \exp (0.665+1.305 \log (E V))] .
\end{gathered}
$$

From the perspective of econometric modelling, (15) and (16) are clearly superior to (12). Since they take account of more features of the data, they are likely to lead to superior predictions of the Banker's offer. It is therefore of considerable interest to investigate whether contestants are taking account of these data features in their own predictions of the Banker's behaviour, or they are content with the simpler rule (12). In order to investigate this question, the estimation procedure outlined in section 5 is repeated, but assuming that contestants form beliefs according to (15) and (16).

Table 6 presents estimates of the model. The results are again presented in two columns. The first column contains the results of the model estimated with all parameters unconstrained. The second shows the results obtained with the parameters of the belief functions constrained by the assumption of rational expectations.

Here, we note that on the evidence of a likelihood ratio test comparing the two columns $\left(\chi^{2}(4)=14.24 ; p=0.008\right)$, there is a significant difference between the parameters actually used by contestants to form beliefs (column 1) and those estimated using all the available information (column 2). This test result amounts to a strong rejection of the rational expectations hypothesis. In particular, the negative estimate of $\gamma_{5}$ in the first column indicates that contestants do not recognise the fact that fifth-round offers are upper-censored.

Given the rejection of this form of the rational expectations hypothesis, it is important to consider what the consequences are of incorrectly assuming it. Firstly, we note that the estimate 
of the risk-attitude parameter $\left(\mu_{r}\right)$ is noticeably larger when rational expectations is assumed, than when estimation is free. This implies that the assumption of rational expectations is causing a bias in the estimation of risk attitude, such that contestants appear to be more risk averse than they truly are. Secondly, the standard deviation of the risk attitude parameter $\left(\sigma_{r}\right)$ is significantly smaller, leading to the conclusion that the rational expectations hypothesis results in biased estimates of the distribution preferences over the population.

\begin{tabular}{|c|c|c|}
\hline & $\begin{array}{l}\text { Estimation with be- } \\
\text { liefs unconstrained }\end{array}$ & $\begin{array}{l}\text { Beliefs formed under } \\
\text { rational expectations }\end{array}$ \\
\hline$\mu_{r}$ & $\begin{array}{c}0.02453 \\
(0.00358)\end{array}$ & $\begin{array}{c}0.03140 \\
(0.00393)\end{array}$ \\
\hline$\sigma_{r}$ & $\begin{array}{c}0.02004 \\
(0.00308)\end{array}$ & $\begin{array}{c}0.02627 \\
(0.00342)\end{array}$ \\
\hline$\sigma_{\varepsilon}$ & $\begin{array}{c}0.01225 \\
(0.00973)\end{array}$ & $\begin{array}{c}0.02884 \\
(0.01279)\end{array}$ \\
\hline$\omega$ & $\begin{array}{c}0.04275 \\
(0.02350)\end{array}$ & $\begin{array}{c}0.03663 \\
(0.03007)\end{array}$ \\
\hline \multicolumn{3}{|c|}{$4^{\text {th }}$ round beliefs equation: off $_{4}()=.\exp \left(\gamma_{4}+\beta_{4} \ln E V().\right)$} \\
\hline$\gamma_{4}$ & $\begin{array}{c}0.52476 \\
(0.14716)\end{array}$ & -0.46000 \\
\hline$\beta_{4}$ & $\begin{array}{c}0.64452 \\
(0.03881)\end{array}$ & 0.85700 \\
\hline \multicolumn{3}{|c|}{$5^{\text {th }}$ round beliefs equation: off $f_{5}()=.\min \left[E V(),. \exp \left(\gamma_{5}+\beta_{5} \ln E V().\right)\right]$} \\
\hline$\gamma_{5}$ & $\begin{array}{l}-1.11559 \\
(0.80626)\end{array}$ & 0.66500 \\
\hline$\beta_{5}$ & $\begin{array}{c}1.12931 \\
(0.21191)\end{array}$ & 1.30500 \\
\hline Number of contestants $(n)$ & 294 & 294 \\
\hline $\begin{array}{l}\text { Average number of choices per } \\
\text { contestant }\end{array}$ & 2.15 & 2.15 \\
\hline Log-likelihood & -232.54020 & -239.65688 \\
\hline
\end{tabular}

Table 6: The table contains the results from the model which incorporates the belief functions defined in (A2.1) and (A2.4) of the Appendix. These definitions are also provided in the table. The assumed utility functional is CARA. The estimation technique used is maximum simulated likelihood. Standard errors are shown in parentheses. Some of the standard errors have been obtained using the delta method. The results are divided into two columns: the first is unconstrained; in the second, the parameters $\gamma_{4}, \beta_{4}, \gamma_{5}$ and $\beta_{5}$ are constrained to satisfy the rational expectations hypothesis, according to (15) and (16).

Anyhow, the Vuong test-statistic (Vuong, 1989) for the null hypothesis that the models in the first columns of Tables 4 and 6 , are equally close to the true model, against the alternative that the first is closer to the true model, is $7.56(N(0,1), p$-value $=0.00000) .{ }^{12}$ Hence we have overwhelming evidence that contestants are forming beliefs using the simpler belief functions (12), in preference to the "superior" functions given by (15) and (16), that make optimal use of the data.

\footnotetext{
${ }^{12}$ For the Vuong tests performed here, we use a correction for the degrees of freedom that corresponds to the Schwarz's Bayesian Information Criterion.
} 
This result has important implications, namely, that it is invalid to assume that beliefs are formed as if all available information is being efficiently processed, and any model that does so is likely to suffer from bias in the estimation of the risk attitude parameter. ${ }^{13}$

\section{Conclusion}

The econometric problem of separate identification of beliefs and preferences in this choice model has been the principal focus of the paper. Our method for dealing with this problem was given an intuitive rationalization in Section 3.2, where we also confirm the validity of the method using a Monte Carlo study. More importantly, we have been interested in whether such beliefs are formed in accordance with the rational expectations hypothesis. In order to test the rational expectations hypothesis, we have compared the belief function estimated within the choice model to the "true" offer function estimated using the complete data set of Banker's offers; two different functional forms have been considered for beliefs.

A problem with this approach that was not raised earlier is that, in order to implement the assumption of rational expectations, we are implicitly assuming that each contestant has access to the complete set of Banker's offers. The obvious logical problem with this assumption is that contestants cannot possibly know what offers are made in future games; they can only know about offers that have been made previously to their own participation. However, we are following other researchers (e.g. Andersen et al., 2006, 2007; Deck et al., 2008; Mulino et al., 2006; Post et al., 2008) in assuming that all information, including future offers, is available.

In any case, the principal objective of this paper has not been to estimate the rational expectations model, but rather to test the rational expectations hypothesis using a more general model. Our unconstrained model is fully flexible in terms of the parameter values in the belief function, which is estimated within the choice model, and therefore should tell us how beliefs are actually formed, on the basis of information which is actually available to the contestant at the time decisions are made. One of our principal findings has been that, at least in the context of Affari Tuoi, the estimates of a simple belief function in the unconstrained model closely match the estimates of the same function obtained from processing of the offer data. Hence we have established that, constraining the choice model to incorporate the extraneously estimated offer function - a practice used routinely by other researchers in this area - results in unbiased estimation of the preference parameters.

However, we also found, in the analysis presented in Section 7, that the rational expectations assumption can be taken a step too far. There, we obtained extraneous estimates of an optimal structure of the offer function - one that incorporates all of the features, for example upper-censoring, that are apparent in the offer data. When such a structure was assumed, we found the unconstrained estimates to be significantly different from the extraneous estimates. Hence we are led to the conclusion that, again in the context of Affari Tuoi, contestants are rational up to a point. They appear to be using all of the information that is available (i.e. all of the offer data), but they do not appear to be using it in an optimal way.

We are not surprised by this result. The assumption of rational expectations is often interpreted in terms of agents having access to all relevant data, and also to the econometric estimation facilities required in order to analyse it. In the present situation, we are finding that, when forming beliefs of the Banker's offer in future rounds, agents do indeed behave as if they have access to all information, and they are able to apply "regression through the origin" correctly. However, their rationality appears to stop there: they appear unable to apply their cognitive estimation abilities to features of the offer data such as upper censoring.

Of course, different conclusions may be reached in the analysis of data from other game shows. Our recommendation to other researchers is that it is always desirable to estimate the belief function in an unconstrained way as a component of the choice model, rather than to rely on prior assumptions about the manner in which such beliefs are formed.

\footnotetext{
${ }^{13}$ Establishing the ways in which agents process information in order to form expectations of others' actions is extremely important in many applications, such as financial analysis. See, for example, Tabak (2009).
} 
Another important conclusion of the paper, established forcefully through the mixture model estimated in Section 6, is that the vast majority of subjects are forward-looking, meaning that they do indeed take into account expectations of the Banker's offer in future rounds when making their choice in the current round. This finding confirms the importance of the role of contestants' beliefs, and of discovering how these beliefs are formed. It also confirms the validity of the forward-looking choice model, estimated in Sections 5, that is the focal point of the paper. 


\section{Appendix 1: Monte Carlo Simulation}

As explained in Section 3.2, the purpose of the simulation is to confirm that the belief functions are separately identifiable from the preference parameters, with choice data only. For the purpose of the simulation, we assume that the game consists of only two rounds, corresponding to the "fourth" and "fifth" rounds of the real game, and that there are 300 contestants. The experiment uses 1000 replications. At each replication, two models are estimated (using MSL): "selection" and "no-selection". The "selection" model assumes (as in the real game) that contestants accepting "deal" in the fourth round do not make a decision in the fifth round. The "noselection" model assumes that decisions are made in both rounds, regardless of the decision in the fourth. The "no-selection" model is clearly not subject to any sort of bias, and so provides a useful benchmark for evaluating the performance of the "selection" model.

\begin{tabular}{|c|c|c|c|c|}
\hline \multicolumn{5}{|c|}{ Model with selection; sample size $=300$} \\
\hline & True value & Mean & Std. Err. & $\begin{array}{l}\text { p-value of } \\
\text { t-test }\end{array}$ \\
\hline Mean risk attitude & 0.02000 & 0.02000 & 0.00006 & 0.9576 \\
\hline Log std. dev. risk attitude & -4.42285 & -4.46636 & 0.00623 & 0.0000 \\
\hline$\beta_{5}$ & 0.55000 & 0.54908 & 0.00283 & 0.7447 \\
\hline Log. Std. Dev. Fechner-error & -2.99573 & -3.00695 & 0.00675 & 0.0969 \\
\hline \multicolumn{5}{|c|}{$\begin{array}{l}\text { Table A1.1: The table reports summary statistics of the Monte Carlo study. The assumed utility functional is } \\
\text { CARA. The beliefs equation assumed is } \tilde{o f f}_{5}(.)=\beta_{5} E V(.) \text {. Number of replications: } 1000 \text {. }\end{array}$} \\
\hline \multicolumn{5}{|c|}{ Model with no-selection; sample size $=300$} \\
\hline & True value & Mean & Std. Err. & $\begin{array}{l}\text { p-value of } \\
\text { t-test }\end{array}$ \\
\hline Mean risk attitude & 0.02000 & 0.02003 & 0.00005 & 0.5702 \\
\hline Log std. dev. risk attitude & -4.42285 & -4.45692 & 0.00544 & 0.0000 \\
\hline$\beta_{5}$ & 0.55000 & 0.55036 & 0.00263 & 0.8910 \\
\hline Log. Std. Dev. Fechner-error & -2.99573 & -3.00652 & 0.00617 & 0.0806 \\
\hline
\end{tabular}

Tables A1.1 and A1.2 contain the results from the "selection" and "no-selection" models respectively. Each model has four parameters. For each parameter, the mean estimate is taken over replications, and this mean compared to the true value of the parameter using a $t$-test. The $p$-values for each $t$-test are shown in the final column of the tables. We see that three of the four parameters appear to be "correctly" estimated in both models. Most importantly, the (mean) risk attitude parameter and the fifth-round belief parameter $\left(\beta_{5}\right)$, are both correctly estimated, even in the situation in which risk-averse contestants are being "selected out" of round 5. The only parameter that is not correctly estimated is the log of the standard deviation of the risk attitude parameter. This parameter represents between-individual heterogeneity. The slight departure of its estimate from its true value is a consequence of the fact that there are only two rounds in this game; at most two observations are available for each contestant. The inconsistency in the estimation of this parameter can of course be avoided by increasing the sample size and/or the number of rounds in the game. Table A1.3 shows results of the same simulation of 
the "selection" model, but with a larger sample size of 2000. Here, we see, as expected, that all four of the parameters are estimated without bias.

\begin{tabular}{ccccc}
\hline \hline \multicolumn{5}{c}{ Model with selection; sample size $=2000$} \\
\hline & True value & Mean & Std. Err. & $\begin{array}{c}\text { p-value of } \\
\text { t-test }\end{array}$ \\
\hline Mean risk attitude & 0.02000 & 0.02001 & 0.00002 & 0.7967 \\
Log std. dev. risk attitude & -4.42285 & -4.42612 & 0.00204 & 0.1091 \\
$\beta_{5}$ & 0.55000 & 0.54866 & 0.00127 & 0.2909 \\
Log. Std. Dev. Fechner-error & -2.99573 & -2.99734 & 0.00228 & 0.4805 \\
\hline \hline
\end{tabular}

Table A1.3: The table reports summary statistics of the Monte Carlo study. The assumed utility functional is CARA. The beliefs equation assumed is off. $\tilde{f}_{5}()=.\beta_{5} E V($.$) . Number of replications: 1000$.

\section{Appendix 2: Modelling the Banker's Offer function}

Here, we provide details of the estimation of the belief functions that are outlined in Section 7. These estimations take account of certain regularities in the offer data that appear under close inspection.

Recall that the key explanatory variable in the determination of the offer is the expected value $(E V)$ of the remaining prizes.

\section{Banker's offer in Round 4}

Figure A2.1 shows a scatter of the round 4 offers against $E V$. A $45^{\circ}$-line is super-imposed. The most obvious feature of the scatter is that the offer rises with $E V$. It is also noticed that the offer is nearly always far below $E V$. A fanning out effect is also evident, with the variance of offers rising as $E V$ rises. In view of the strong positive skew seen in both variables, it is appropriate to take logarithms before analysing the relationship. Figure A2.2 shows a scatter of the logged variables. Here we see that the relationship is clearly log-linear. The plot also appears homoscedastic. We therefore estimate the straightforward log-linear regression:

$$
\log (\text { offer })=\gamma_{4}+\beta_{4} \log (E V)+u \text {, }
$$

where the 4 subscripts are present since we are restricting attention to round 4 . The results from estimation of (4) are:

$$
\begin{aligned}
& \log (\text { offer })=-0.460+0.857 \log (E V) \\
& n=252
\end{aligned}
$$

We may deduce from this estimated regression equation that contestants who form rational expectations use the following formula for the expected offer in round 4 :

$$
\text { offer }=\exp [-0.460+0.857 \log (E V)] \text {. }
$$




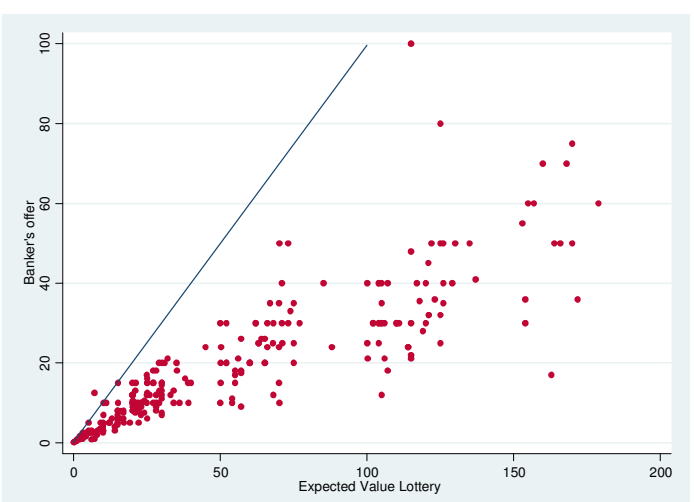

Figure A2.1: Offer against expected value in round $4.45^{\circ}$-line superimposed.

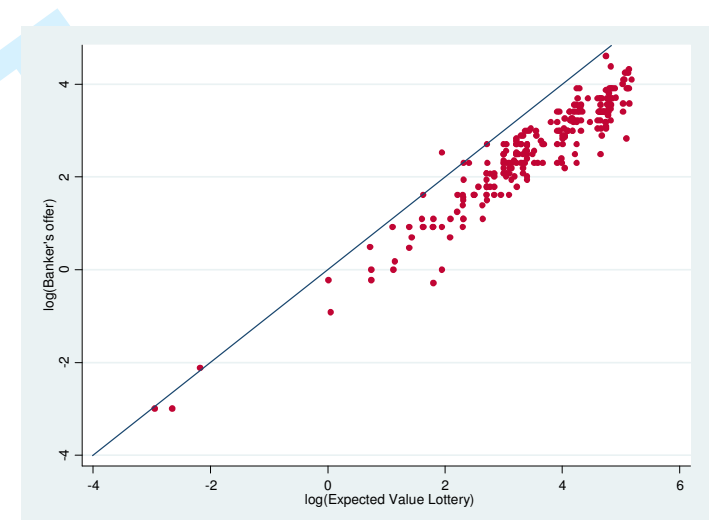

Figure A2.2: Logarithm of offer against logarithm of expected value in round $4.45^{\circ}$-line superimposed.

\section{Banker's Offer in Round 5}

Figure A2.3 shows offer against expected value for all offers made in round 5. A $45^{0}$-line is again super-imposed. Again it is also clear that the offer rarely exceeds the expected value. However, a difference from round 4 is that some points appear to be on (or very close to) the $45^{0}$-line, implying that the offer exactly equals the expected value. We shall treat these observations as upper-censored observations. Note that this censoring tends to arise when the expected value is comparatively low. When the expected value is high, the offer is usually below the expected value. Note also that there is one observation above the $45^{\circ}$-line. This observation is interpreted as errant behaviour on the part of the Banker, and is omitted from the censored regression reported below.

Figure A2.4 shows the scatter of the logged variables. The censoring that was apparent in figure A2.3 is even more clearly apparent in figure A2.4, with a sizable portion of the sample appearing to be on the $45^{0}$-line.

We estimate the following censored regression model (omitting the one observation that is above the $45^{0}$ line):

$$
\begin{aligned}
& \log (\text { offer })=\gamma_{5}+\beta_{5} \log (E V)+u \quad \text { if } \quad \gamma_{5}+\beta_{5} \log (E V)+u<\log (E V) \\
& \log (\text { offer })=\log (E V) \quad \text { if } \quad \gamma_{5}+\beta_{5} \log (E V)+u \geq \log (E V) \\
& u \sim N\left(0, \sigma_{u}^{2}\right)
\end{aligned}
$$

where the 5 subscripts are present since we are restricting attention to round 5 . The results from this censored regression model are: 
$\log ($ offer $)=0.665+1.305 \log (E V)$ $(0.081)(0.358)$

$n=106$

34 uncensored observations

72 right-censored observations

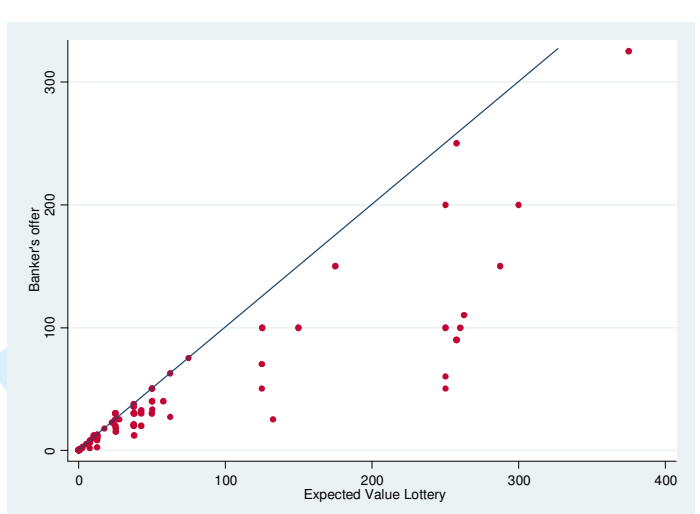

Figure A2.3: Offer against expected value in round 5. $45^{\circ}$-line superimposed.

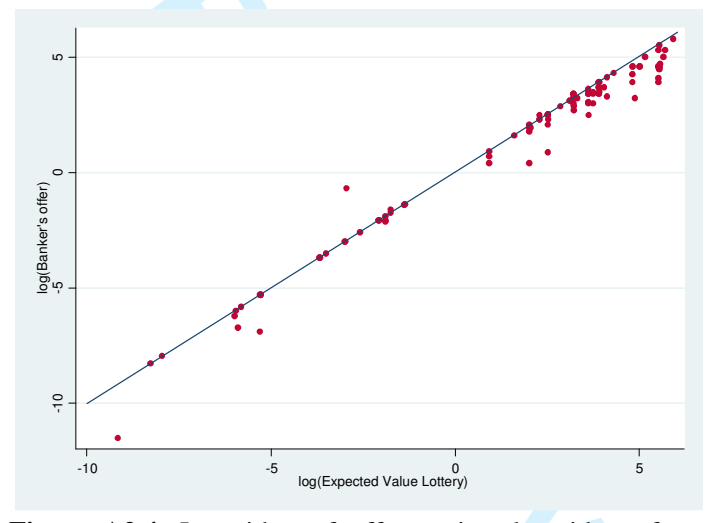

Figure A2.4: Logarithm of offer against logarithm of expected value in round $5.45^{\circ}$-line superimposed.

We deduce the following formula for predicted offer in round 5 :

$$
\text { offer }=\min [E V, \exp (0.665+1.305 \log (E V))] .
$$




\section{References}

Andersen, S., Harrison, G. W., Lau M. I. and E. E. Rutström (2006) "Dynamic choice behavior in a natural experiment", University of Central Florida, Economics Department, working paper 06-10, 1-54.

Andersen, S., Harrison, G. W., Lau M. I. and E. E. Rutström (2007) "Risk aversion in game shows", J. C. Cox and G. W. Harrison (eds.), Risk Aversion in Experiments (Greenwich, CT: JAI Press, Research in Experimental Economics, Vol. 12)

Araña, J.E. and C.J. León (2006) "Modelling unobserved heterogeneity in contingent valuation of health risks," Applied Economics, 38, 2315-2325.

Attfield C. L. F., D. Demery and N. W. Duck, 1991, Rational Expectations in Macroeconomics, Second Edition, Blackwell, Oxford, UK.

Avery R. B., L. P. Hansen and V. J. Hotz, (1983), "Multiperiod probit models and orthogonality condition estimation", International Economic Review, 24, 21-35.

Beetsma, R. and Shotman P. (2001), "Measuring risk attitudes in a natural experiment: data from the television game show Lingo", Economic Journal, 111, 821-848.

Bellemare, C., Kröger, S. and A. van Soest (2008), "Measuring Inequity Aversion in a Heterogeneous Population Using Experimental Decisions and Subjective Probabilities," Econometrica, vol. 76(4), 815-839.

Blavatskyy, P. and G. Pogrebna (2010) "Endowment Effects? "Even" with Half a Million on the Table!," Theory and Decision, 68, 173-192.

Bombardini, M., Trebbi, F., "Risk aversion and EU theory: a field experiment with large and small stakes", Journal of the European Economic Association, forthcoming.

Bone, J.D., Hey, J.D. and J.R. Suckling (2003) “Do people plan ahead?" Applied Economics Letters, 10, 277-280.

Botti, F., Conte, A., Di Cagno, D. and D'Ippoliti, C. (2007), "Risk aversion, demographics and unobserved heterogeneity. Evidence from the Italian TV Show "Affari Tuoi"", in Innocenti A. e Sbriglia P. (eds.), Games, Rationality and Behaviour, Houndmills: Palgrave MacMillan.

Botti, F., Conte, A., Di Cagno, D. T. and C. D'Ippoliti (2008) "Risk Attitude in Real Decision Problems," The B.E. Journal of Economic Analysis \& Policy: Vol. 8: Iss. 1 (Advances), Article 6.

Conte, A., Hey J.D., and Moffatt. P.G. (2009) "Mixture models of choice under risk" Journal of Econometrics, doi:10.1016/j.jeconom.2009.10.011 (in press).

Deck, C., Jungmin, L. and J. Reyes, (2008), "Risk attitude in large stake gambles: Evidence from a game show", Applied Economics, Vol. 40, pp. 41-52.

de Roos, N. and S. Sarafidis (2010), "Decision making under risk in Deal or No Deal", Journal of Applied Econometrics 25(6), 987-1027.

Durbin, J. (1953), "A note on regression when there is extraneous information on one of the coefficients", Journal of the American Statistical Association, 48, 799-808.

Friend, I., and Blume M. B. (1975), "The demand for risky assets", American Economic Review, 65, 900-922.

Gertner, R. (1993) "Game shows and economic behaviour: risk taking on "Card sharks",, The Quarterly Journal of Economics, 108, 507-521.

Godfrey, L.G. (1988). Misspecification testing in econometrics (Cambridge).

Harrison, G. W., and Rutström E. E. (2009), "Expected Utility Theory and Prospect Theory: One Wedding and A Decent Funeral", Experimental Economics, vol. 12.

Hartley, R. G., Lanot and I. Walker (2005), "Who really wants to be a millionaire: estimates of risk aversion from game show data", Working Paper $n$. 719, University of Warwick, Department of Economics.

Hey, J. D. and C. Orme (1994), "Investigating generalizations of expected utility theory using experimental data“, Econometrica, 62(6), 1291-1326. 
Holt, C. A. and S. K. Laury (2002), "Risk aversion and incentive effects", American Economic Review, 92, 1644-55.

Lerman, S. and C. Manski (1981), "On the use of simulated frequencies to approximate choice probabilities," in C. Manski and D. McFadden eds. Structural Analysis of Discrete Data with Econometric Applications, Cambridge, Mass.: M.I.T. Press.

Loomes G., P.G. Moffatt, and R. Sugden (2002), "A microeconometric test of alternative stochastic theories of risky choice", Journal of Risk and Uncertainty, 24, 103-130.

Manski, C. F. (2002), "Identification of decision rules in experiments on simple games of proposal and response", European Economic Review, Vol. 46, No. 4, 880-891.

Manski, C. F. (2004), "Measuring expectations", Econometrica, Vol. 72, No. 5, 1329-1376.

Metrick, A. (1995), "A natural experiment in "Jeopardy!"”, American Economic Review, 85(1), 240-253.

Moffatt, P. G. and S. A. Peters (2001), "Testing for the presence of a tremble in economic experiments", Experimental Economics, 4, 221-228.

Mulino, D., Scheelings, R., Brooks, R. and R. Faff (2006), "An empirical investigation of risk aversion and framing effects in the Australian version of Deal or No Deal", Working Paper, Department of Economics, Monash University.

Oehlert, G. W. (1992), “A Note on the Delta Method," The American Statistician, 46(1), 27-29.

Post, T., van der Assem, M., Baltussen, G. and R. Thaler, (2008), "Deal or not deal? Decision making under risk in a large-payoff game show", American Economic Review, vol. 98(1), 38-71.

Rutström, E. E. and Wilcox (2009), "Stated Beliefs Versus Empirical Beliefs: A Methodological Inquiry and Experimental Test", Games and Economic Behavior, Elsevier, vol. 67(2), 616-632.

Tabak, B. (2009), "Testing the expectations hypothesis in the Brazilian term structure of interest rates: a cointegration analysis," Applied Economics, 41, 2681-2689.

Train, K. (2003), Discrete choice methods with simulation, Cambridge: Cambridge University Press.

Vuong, Q. H. (1989), "Likelihood ratio tests for model selection and non-nested hypotheses", Econometrica, Vol. 57, No. 2, 307-333.

Yassour, J., D. Zilberman, G. C. Rausser (1981), “Optimal Choices among Alternative Technologies with Stochastic Yield”, American Journal of Agricultural Economics, 63, 718723. 